\title{
THE STEEL TRUSS TOWER (DERRICKS) STRUCTURE EVALUATION IN BUCKLING ANALYSIS
}

\author{
Miftahul Iman \\ Program Studi Teknik Sipil Universitas Borneo Tarakan, Tarakan \\ Jl. Amal Lama No.01 Kec. Tarakan Timur Tarakan Kalimantan Utara \\ E-mail: miftah@borneo.ac.id
}

\begin{abstract}
Tarakan was an oil-producing city had been known since 1896 that were explored in first time in authorized by Bataavishe Petroleum Maatchapij (BPM). The derrick was a petroleum drilling facility that were performed in steel truss structure. The derrick prototype had been modeled in 3D truss by utilizing SAP2000. The models had been classified into 2 models: perfect and imperfect models. The imperfections denoted by the percentage of elements loses (IM20, IM24), and IM16). Buckling analysis consisted in linear and nonlinear analysis had been evaluated. The 3D solid model (Abaqus) also performed for single element buckling. The results showed that perfect derrick model satisfied the strength and stability requirement. The percentage of element loss reduced the capacity 9.45\%-37.83\%. The IM16 model buckled at $4.27 \mathrm{~T}$ were based on nonlinear analysis and $18.50 \mathrm{~T}$ were based on linear analysis. The single elemen buckling was $20,63 \%$ of the largest compressive element.
\end{abstract}

Key words:: buckling, on shore, capacity, wind, derrick

\section{INTRODUCTION}

Tarakan was one of the oil-producing cities that have been known since 1896. The first oil exploration activity in Tarakan was initiated by Bataavishe Petroleum Maatchapij (BPN). So much oil drilling infrastructure (derrick) had been built and most of them still be found now. Due to the time, some of these derricks had been no longer in used. The placement of the derricks were closed to the critical public trajectories transportation and the electricity transmission networks. This situation cause the disaster probably when the existing derrick was failure. The environmental loads such as wind load and earthquake load should be considered. The effect of the environmental load can influence the instability and its capacity reduction due to aging.

So many regulations and requirements (codes) for steel construction that should be referenced for conducting the forensic engineering actions. This is too difficult to find out the information about what code that was used in the past time. Some load combinations that was used in the design previously could not matched today. The advanced structure analysis was also be carried out easily to determine the effect of structural instability due to imperfections. The imperfection in this research was considered in the element loss of the derricks. In addition, the number of numerical applications based on finite element method made this forensic engineering activity easier with accuracy that was considered. Some computer applications based on finite element methods were available, SAP2000 is one of them.

Dacovic and Hegedic (2014) conducted research on risk management approaches in oil and gas on shore construction activities on land. The results showed that a detailed quality approach from the risk management process is associated with risk difficulties to the quantity of experiential knowledge with a very limited risk approach in mitigating construction of oil and gas construction. The results also indicate a significant difference in the contingency of activities when two different risk management approaches are established. Miftahul et.all (2019) had studied the effect of the pitting corrosion, an extremely localized corrosion that leads to the creation of small holes in metal could trigger structural failure in platform structures. The results showed that the overall buckling capacity of the truss were compared to similar truss based on the element buckling of compression element in the truss model with various hole positions, the overall buckling loads were slightly higher than that of element buckling loads. Solazzi and Zrnić (2017) have 
conducted research on designing a very large crane (main boom is $80 \mathrm{~m}$ in length and payload is $60 \mathrm{~T}$ ) by considering the dynamic effect caused by the load transfer process. This research was developed through an analytical calculation model for the initial design of the crane and using different finite element analysis (FEM) to evaluate the dynamic behavior of the crane. The results also show that the buckling phenomenon is the most critical point of view for this type of crane.

\section{RESEARCH METHOD}

The numerical model used in this study is a 3D frame model available in the SAP 2000. The prototype modeled in this study was a prototype of a terrestrial oil drilling tower structure (derrick) built on land by the Dutch colonial government in the city of Tarakan (Figure 1).

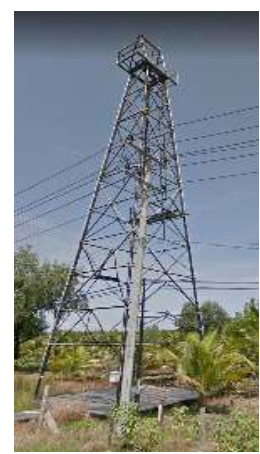

Figure 1 Derrick prototype

Numerical modeling in this study was generally grouped into 2 namely perfect numerical models (Perfect Model) and imperfect numerical models (Imperfect Model). Both models had been performed in static analysis, equivalent static analysis (earthquake) and buckling analysis. Each analysis produced internal forces, deformations, and displacements so that they can be compared with each other.

Perfect model is a structural model of a steel frame tower (derrick) which is intact without any damage and the elements complete. Perfect model was built based on reconstructions based on their actual condition. Material data used the A36 steel material type $\left(F_{y}=36 \mathrm{Ksi}\right.$ and $\left.F_{u}=58 \mathrm{Ksi}\right)$. The model built was assumed to have the similar performance and quality when the derrick prototype was built first (Figure 2).

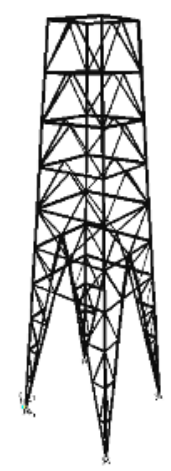

Figure 2 Perfect derrick model

Imperfect models were structural models of steel frame towers (derrick) with imperfect structural element configurations. The imperfections of the derrick structure were indicated by the reduction of the element in the structural system. Imperfect prototype consisted of 3 consecutive models namely IM20, IM56, and IM24 (Figure 3). Each submodel was distinguished based on the missing elements of the derrick frame structure.

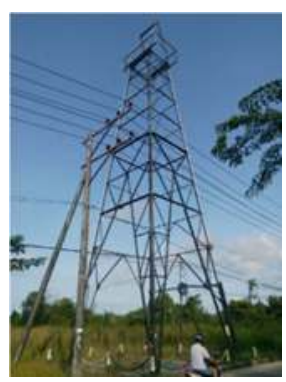

(i)

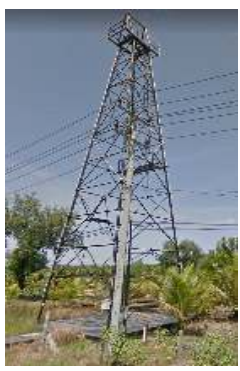

(ii)

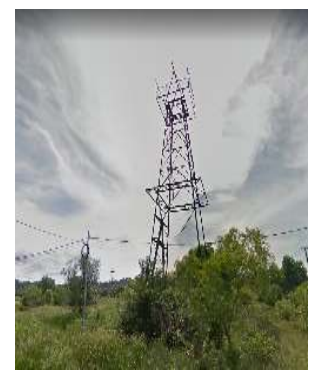

(iii)

Figure 3 Imperfect derrick model 
This study used models that were inspired prototype supporting framework (derrick) where located in district 4, Tarakan city, Indonesia. The models were built up based on the prototype in full scale numerical model. The geometric data (dimensions and height profile derrick) had been approximated. Material property data refered to current standards (AISC 2010). The loading data was obtained from the wind speed data which processed into a load based on an equation determined by ASCE/SEI 7-10. The wind data itselves came from the Meteorology, Climatology and Geo Physics (BMKG) Tarakan city, Indonesia.

$$
F=q_{z} G C_{f} A_{f}
$$

where:

$q_{z}$ : velocity pressure evaluated at height $z$

$G$ : wind blowing effect factor

$\mathrm{C}_{\mathrm{f}}$ : force coefficient

$A_{f}:$ the area of the projection is perpendicular to the wind except where $C_{f}$ was determined for the actual surface area, in $\mathrm{ft}^{2}\left(\mathrm{~m}^{2}\right)$

Data analysis was performed in SAP2000 which already has features of profile types from various standards that apply in several countries. The analysis used in this study is the AISC-ASD 1989, AISC-LRFD 1993, and AISC 2010 methods. The use of these methods is as a standard approach used at the beginning of the derrick structure constructed and the relevance of the design to the actual conditions

\section{RESULTS AND DISCUSSION}

The comparison of imperfect models (IM20, IM24, and IM16) included: internal forces and displacement. An imperfect model comparison was determined based on the reduced number of frame elements. Some imperfect models have been compared in axial force values based on the percentage of element loses in the incompleted steel truss tower (derrick) structure model. Normal force can be divided into pull and force.

Figure 4 showed the comparison curve of the force decrease in the normal force of each imperfect model. A load combination curve of 1.4D and a load combination of 0.9D + $\mathrm{W}$ showed a decrease in the normal tensile force as the number of elements in an imperfect model decreased. The percentage decrease in normal tensile strength respectively for the combination is $12.657 \%$ and $9.45 \%$ (1.4D) and $19.19 \%$ and $-4.47 \%(0.9 D+W)$.

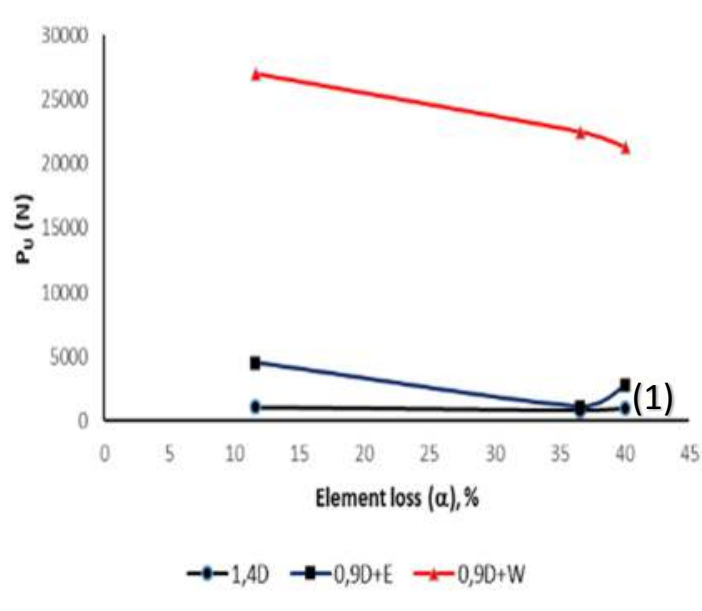

(i)

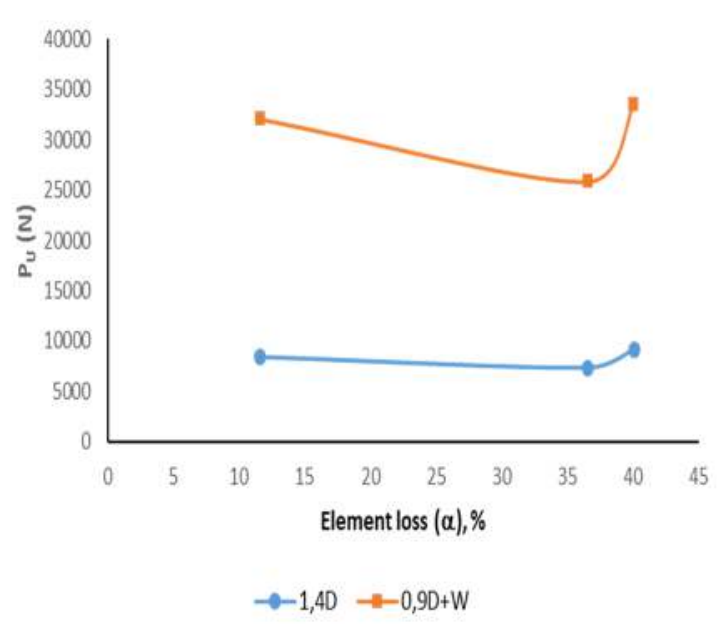

(ii)

Figure 4 Normal tensile force curve

Figure 5 showed the comparison curve of the normal compressive force decreased due to the element loses in the imperfect model. The load combination curve of $1.4 D$ and a load combination of $0.9 D+W$ showed a decrease in the normal tensile force as the number of elements in an imperfect model decreased. The percentage decreased in the normal tensile strength respectively for the load combination 
had been recorded correspondently in $12.657 \%$ and $9.45 \%(1.4 D)$ and $19.19 \%$ and $-4.47 \%$ $(0.9 D+W)$. The load combination involved dead $(D)$ and $(W)$ load that was carried on the steel truss (derrick) structure.

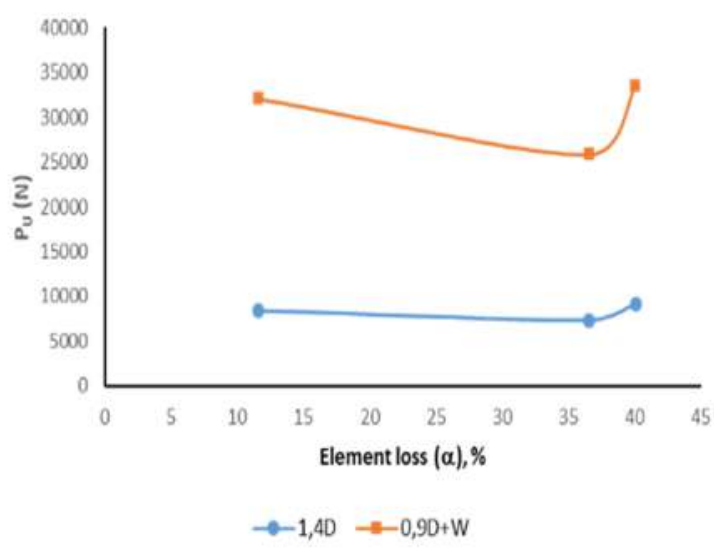

(i)

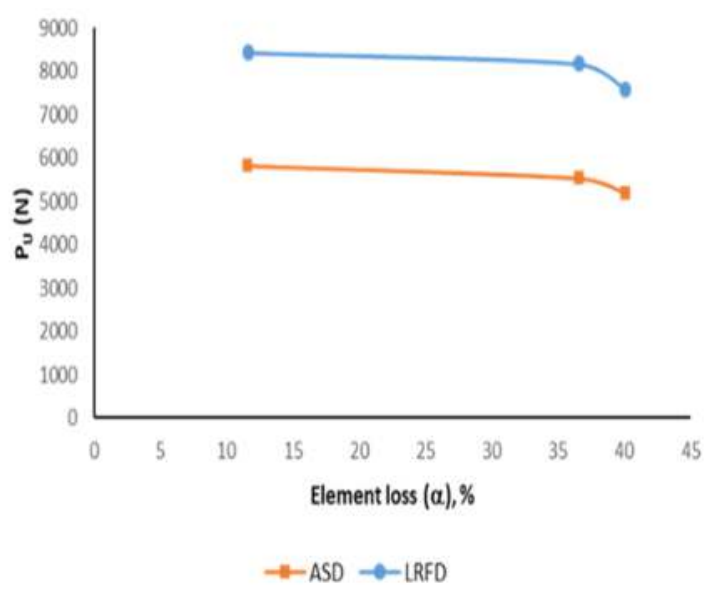

(ii)

Figure 5 Normal compressive force curve

The imperfect model has been compared to the maximum displacement value that was occured based on the percentage of element loses in the imperfect model of derrick structure. The displacements had been divided into $\mathrm{x}$ direction displacement and $\mathrm{y}$ direction displacement (Figure 6).

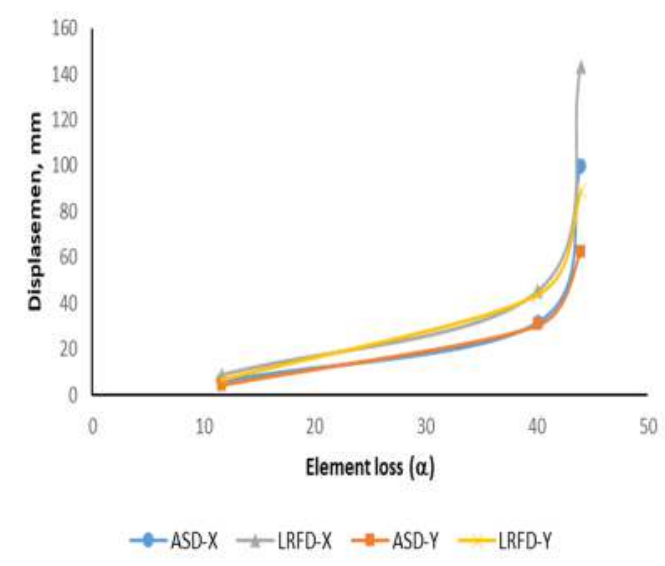

Figure 6 Displacement comparison curve

Comparison of perfect and imperfect models included element forces analysis and displacement. The number of elements in a perfect derrick structure model had been counted were 232 frame elements.

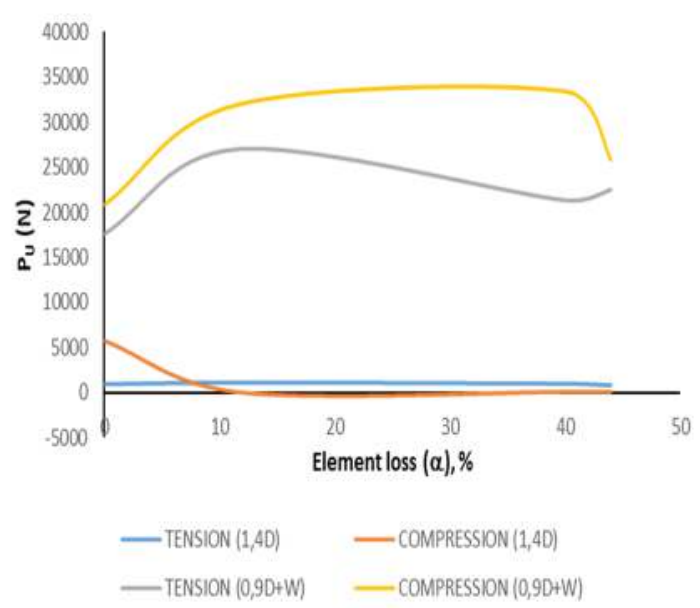

Figure 7 Internal forces curves (LRFD)

Figure 7 showed the comparison curve of forces in a perfect model and an imperfect model. The forces in the perfect model had been steel above the values of the forces in the imperfect models. The forces in (tension and compression) the perfect model are below the value of the forces in the imperfect model for forces in the compression. That is due to the elements loses resulted in increased internal force on the other elements to achieve the structural system stability (stability). 


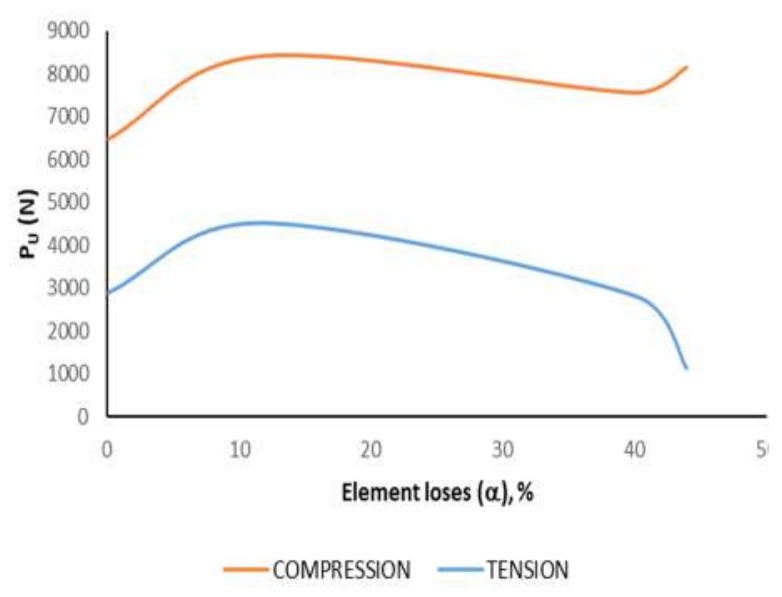

Figure 8 Earthquake internal forces (LRFD)

Figure 8 showed the comparison curve of internal forces due to earthquake load of a perfect and an imperfect model. The forces in (tension and compression) the perfect model were below the value of the forces in the imperfect model. That is due to the reduced element loses resulted in increased force on the other elements to achieve a structural system balance (equilibrium). This condition can also be caused by the work direction of the earthquake load which was different from the work direction of the wind load.

This study also discussed the reduction in buckling capacity of all models based on linear and nonlinear analysis ( $P$ delta with large displacement). The buckling was considered in two groups: element buckling (3D solid) and overall structural buckling (3D frame element). The decreased in buckling capacity were presented in nonlinear P-delta curve (Figure 10).

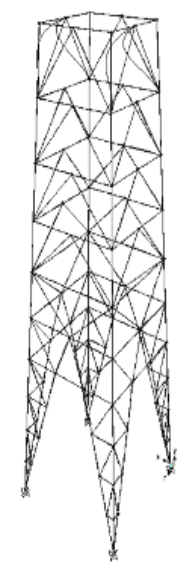

(i)

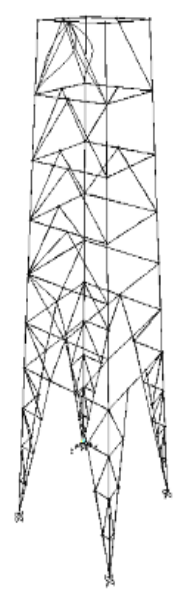

(ii)

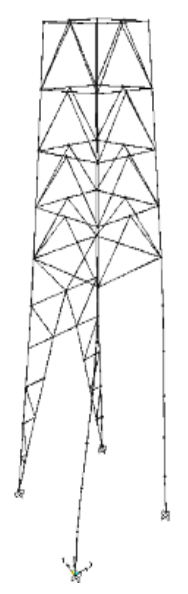

(iii)

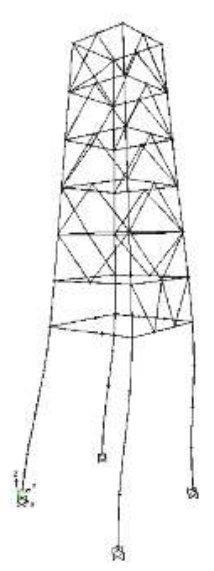

(iv)

Figure 9 Buckling pattern at first mode

Figure 9 showed buckling pattern of every models (PM,IM20,IM24, and IM16). The buckling was occurred in bracing element only 
in Figure 9(i) and 9(ii). The overall structure buckling when the bracing elements in legs of the derrick structure were disappeared (Figure 9(iii) and Figure 9(iv)). This showed how importance the bracing element for the derrick structure stability.

Table 1 The Cricitical load (Pcr)

\begin{tabular}{lcc}
\hline Model & \multicolumn{2}{c}{ Critical Load (\%) } \\
& Linear & Nonlinear \\
& & - \\
Perfect Model & - & 15,64 \\
IM20 & 13,12 & 95,71 \\
IM24 & 83,34 & 92,08 \\
\hline
\end{tabular}

Table 1 showed due the bracing element losses reduced the bending capacity. Low buckling capacity indicated that the structural system has failed to buckle. The buckle in the structure system occured when they achieved their critical load. The critical load value in the IM16 model is much lower because the configuration of the frame elements in the IM16 model made it easier for the structural system to reach the critical load $(23130 \mathrm{~N})$ for nonlinear structure analysis.

Table 1 also showed the differences in the value of the critical load results from the linear buckling analysis (eigen value) and nonlinear buckling analysis with the large displacement Pdelta curve. The value of the critical load results from the nonlinear static analysis was lower than the results of the linear buckling analysis. The percentage difference in the value of critical load results from nonlinear analysis to the results of linear buckling analysis below: $2.93 \%$ (Perfect); 5.74\% (IM20); 74.99\% (IM24); and 76.93\% (IM16).

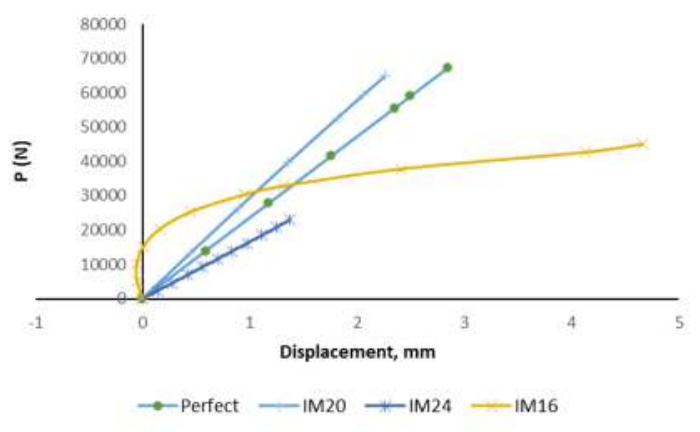

Figure 10 Load-displacement curves

Figure 10 showed the comparison of load- displacement $\left(U_{3}\right)$ curves with large displacement. The critical load values had been determined based on asymptotically nonlinear Pdelta curves. Based on Figure 10, only the IM16 model got global buckling at (42654.9 N). The buckling analysis in this case uses service load (D).

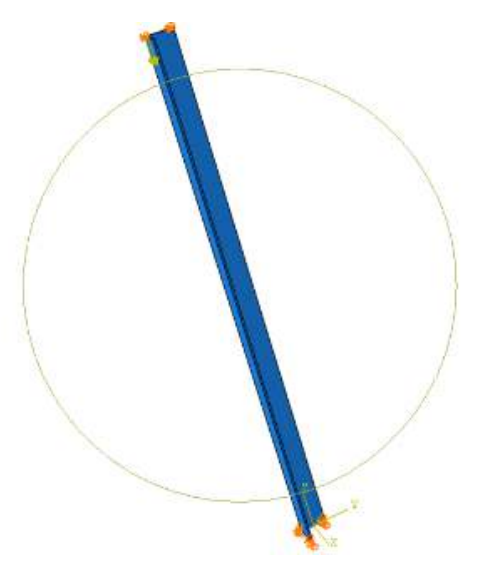

(i)

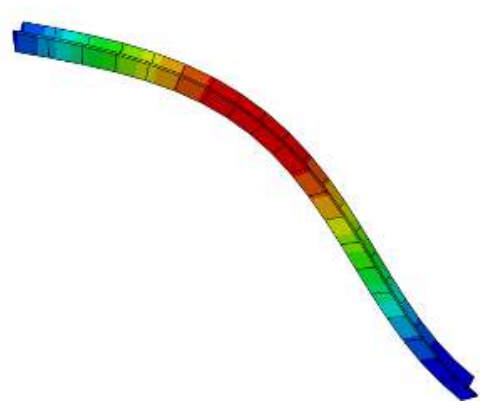

(ii)

Figure 11 3D solid element

Figure 11 showed the 3D solid element (Lx4x4x5/16) for bracing and legs element of the derrick structure. Load and boundary condition had been shown in Figure 11(i). The bucling pattern showed single curvature as like as Euler buckling pattern in first mode (Figure 11(ii)). The critical load (eigen value) was $6783,40 \mathrm{~N}(0,67 \mathrm{~T})$ and $20 \%$ lower then its element capacity (internal compressive force).

\section{CONCLUSSION}

Based on the results of numerical modeling of the steel frame tower structure system (derrick), the following conclusions can be list below:

In general, the steel frame tower structure (derrick) satisfied the security requirements for fixed load conditions, 
earthquake loads, and wind loads provided that the legs element should be strengthened by the addition of cross-sectional dimensions and the use of bracing elements. The compression force carried on the element of derrick structure system was larger than the internal tension force with any combination of loads, The higher percentage of loss of the element produced the lower capacity of cross section correspondently $23.67 \%$ and $9.45 \%$ (1.4D); $16.68 \%$ and $21.11 \%$ $(0.9 D+W) ; 75.15 \%$ and $37.83 \%(0.9 D+E)$. The effect of the earthquake load becomes significant when the elements of derrick decreased. The derrick structure systems were vulnerable to the risk of structural buckling failure (overall buckling) due to the reduced the elements derrick. The IM16 model has buckled at $42654.93 \mathrm{~N}$ (4.27 Ton) load based on the results of nonlinear analysis and $184895.22 \mathrm{~N}$ (18.50 Ton) based on linear buckling analysis (eigen value). The element buckling (L4X4×5/16) lower than overall structural buckling above $20 \%$ in the case of the derrick structure system.

\section{ACKNOWLEDGEMENT}

The authors thanks Dr.-Eng Fikris Haris, S.T., M.Eng for permitting and supporting SAP2000 licence in Computer Laboratory of Civil Engineering and Environment Departement, Gadjah Mada University.

\section{REFERENCES}

ASCE SEI 7-10, Minimum Design Loads for Buildings and Other Structures: American Society of Civil Engineering, 2010, pp. 320.

AISC ASD, Specification for Structural Steel Buildings Allowable Stress Design and Plastic Design: American Institute Steel Construction, 1989, pp. 40-44.

AISC LRFD, Load and Resistance Factor Design Specification for Structural Steel Buildings: American Institute Steel Construction, 1993, pp. 36-41.

AISC LRFD, Specification for Structural Steel Buildings ANSI/AISC 360-10: American Institute Steel Construction, 2010, pp. 3641.

Dakovic, M. and Hegedic, M. Risk Management Approaches in Oil and Gas Onshore Constructions Projects (Project Management), Faculty of Mechanical Engineering and Naval Architecture University of Zagreb Croatia. Product Development, Production Technologies,
2014

Luigi Solazzi. and Nenad Zrnić. Design of a High Capacity Derrick Crane Considering The Effects Induced by Load Application and Release. Original Scientific Paper, 409, 2017, pp. 15 - 24.

Miftahul I., Bambang S., Priyosulistyo HRc., Muslikh. Experimental and numerical investigations on overall buckling of steel pipe truss with circular cutout on the compression element. M ATEC Web of Conference, 258, 2019, pp. 1-7. 